\title{
An Unconscious Desire for Hierarchy? The Motivated Perception of Dominance Complementarity in Task Partners
}

\author{
Larissa Z. Tiedens \\ Stanford University
}

\author{
Miguel M. Unzueta and Maia J. Young \\ University of California, Los Angeles
}

\begin{abstract}
In 6 studies, the authors examined the perception of dominance complementarity, which is the perception of a target as different from the self in terms of dominance. The authors argue that these perceptions are motivated by the desire for positive task relationships. Because dominance complementarity bodes well for task-oriented relationships, seeing dominance complementarity allows one to be optimistic about a work relationship. As evidence that perceptions of dominance complementarity are an instance of motivated perception, the authors show that complementary perceptions occur when participants think about or expect task-oriented relationships with the target and that perceptions of dominance complementarity are enhanced when individuals care about the task component of the relationship.
\end{abstract}

Keywords: complementarity, hierarchy, dominance, task orientation, interpersonal theory

People are not objective perceivers of the world. Instead, they take advantage of ambiguities in stimulus properties to see objects and people in a way that confirms their hopes, desires, and expectations. Numerous demonstrations of this kind of motivated perception have been provided in the literature (see Kunda, 1990). The most typical examples concern perceptions of the self and show that people see themselves in a particularly flattering light (Sedikes, 1993; Taylor \& Brown, 1988). In addition, people's perceptions of other people can also be influenced by motivations. For example, self-serving motives can result in perceiving others as less valuable than the self (Dunning, Meyerowitz, \& Holzberg, 1989). However, not all motivated perceptions of others are derogatory to the target. For example, a number of studies have shown that anticipated social interaction increases the perceived attractiveness and likeability of the target (Berscheid, Brothen, \& Graziano, 1976; Darley \& Berscheid, 1967; Mirels \& Mills, 1964; Tyler \& Sears, 1977), suggesting that people upgrade their perception of others when doing so allows them to be optimistic about future experiences. Murray and colleagues (Murray, 1999) have demonstrated that people also have quite flattering views of romantic relationship partners. People provide more positive descriptions of their romantic relationship partners than those relationship partners provide of themselves, people project their image of an ideal partner onto their current partner, they see their own partner as better than most partners (Murray, Holmes, \& Griffin, 1996), and they reinterpret the faults of their partner as virtues (Murray \& Holmes, 1993, 1999). People also have a tendency to see others as

Larissa Z. Tiedens, Graduate School of Business, Stanford University; Miguel M. Unzueta and Maia J. Young, Anderson School of Management, University of California, Los Angeles.

Larissa Z. Tiedens was supported by the Spence Faculty Fellowship and the Fletcher Jones Faculty Fellowship. We thank the members of Lara Lab and Brian Lowery for helpful comments on drafts of this work. We also are grateful to Marcelino Clarke for his assistance in creating materials.

Correspondence concerning this article should be addressed to Larissa Z. Tiedens, Graduate School of Business, Stanford University, $518 \mathrm{Me}-$ morial Way, Stanford, CA 94305-5015. E-mail: 1tiedens@stanford.edu similar to themselves (Krueger \& Clement, 1994), and this is particularly true when that other person shares a social connection, such as a group membership (Clement \& Krueger, 2002) or a romantic relationship (Murray \& Holmes, 1993, 1999). The mere anticipation of an interaction with another also fuels perceptions of similarity (Miller \& Marks, 1982). Given the well-established link between similarity and relationship success (Byrne, 1971), these assimilation effects may also be examples of motivated perception. In all, this body of research has suggested that people see actual and potential relationship partners in a manner that supports their desires to have good relationships (Baumeister \& Leary, 1995; Murray \& Holmes, 1999).

In this article, we also examine how the desire for positive relationships can influence perceptions of potential interaction partners. However, our work differs from previous research in important ways. First, we suggest that in some relational settings people have an unconscious desire or motivation for hierarchically differentiated relationships. On the basis of previous research (reviewed below), we believe that people sometimes experience hierarchy as more enjoyable and productive than nonhierarchical relationships, and as such, we argue that people's desire for positive relationships can manifest itself in the perception of others as hierarchically differentiated from the self. Thus, we predicted that, in these relational settings, the more dominant an individual perceives herself or himself to be, the less dominant she or he would perceive a potential interaction partner to be and that the less dominant an individual perceives herself or himself to be, the more dominant she or he would perceive a potential interaction partner to be. This pattern, which we call dominance complementarity diverges from previous findings concerning the motivated perception of others in two ways: (a) individuals perceive a potential interaction partner differently from, rather than similarly to, the self and (b) individuals are fulfilling their relationship motivation at times by perceiving the relationship partner more negatively (i.e., as more submissive) and at other times by perceiving the relationship partner more positively (i.e., as more dominant). Viewing a potential interaction partner as contrasting with the self in terms of dominance is akin to perceiving informal hierarchical 
differentiation. Thus, evidence for perceptions of dominance complementarity and, especially, evidence that these perceptions emerge from the desire for good task-oriented relationships imply that people are motivated to create interpersonal hierarchies in task-oriented settings.

\section{Dominance Complementarity}

\section{Defining Dominance Complementarity}

The term dominance complementarity has its roots in interpersonal theory (Carson, 1969; Kiesler, 1983; Leary, 1957). Interpersonal theory forwarded the idea that there are two primary dimensions of interpersonal behavior: an affiliation dimension and a dominance dimension. The affiliation dimension refers to the degree to which a person is agreeable or quarrelsome or behaves in an agreeable fashion versus a quarrelsome fashion. The dominance dimension refers to the degree to which a person is dominant or submissive or behaves in a dominant fashion versus a submissive fashion. Interpersonal theorists defined interpersonal complementarity as instances in which interaction partners were similar in terms of affiliation (an affiliation effect) but different in terms of dominance (a contrast effect). They argued that complementarity characterizes most relationships, particularly successful relationships. Interpersonal theorists suggested that people tend to respond to others in a complementary way and that when they do so, the relationship is strengthened and is experienced as more pleasant. As described by Horowitz and his colleagues (Horowitz, Dryer, \& Krasnoperova, 1997; Horowitz et al., 2006) behavior along these dimensions functions as an invitation to the partner to act in a particular way (i.e., the complementary way). When an interaction partner accepts the invitation and acts in the complementary fashion, both interaction partners feel a sense of interpersonal understanding, cooperation, and liking.

In this article, we use the phrase dominance complementarity because we are particularly concerned with the dominance component of complementarity. We think this aspect of interpersonal complementarity is particularly interesting because it is distinct from other findings regarding the association of self and close others (which have tended to focus on assimilative effects) and because it is related to the creation of informal interpersonal hierarchies within a relationship. Although we focus on dominance complementarity, most of the studies (1-5) also include data regarding the affiliation dimension. The affiliation data provide a useful way of assessing whether the effects we uncovered are particular to the dominance dimension (as we suggest) or generalizable to any trait dimension.

\section{The Appeal of Dominance Complementarity}

In a number of studies, it has been found that when participants work on a task with either another participant or a confederate, they will display behavior that complements their partner's behavior (Locke \& Sadler, 2007; Markey, Funder, \& Ozer, 2003; Sadler \& Woody, 2003; Strong et al., 1988; Tiedens \& Fragale, 2003; Tracey, 1994). Further, the positive interpersonal consequences of dominance complementarity, suggested by interpersonal theory, have been documented in existing research. For example, Dryer and Horowitz (1997) found that participants discussing interpersonal issues (Study 1) or solving a problem (Study 2) were more satisfied with the interaction if they were paired with a complementary partner than if they were paired with a noncomplementary partner. Further, Tiedens and Fragale (2003) found that participants liked a confederate more and were more comfortable when that confederate complemented rather than mimicked the participant's dominant and submissive nonverbal behavior. Thus, the literature on complementarity suggests that the well-known association between similarity and liking (e.g., Byrne, 1971, 1997) does not apply to all dimensions. Although the affiliation dimension promotes similarity, which then produces attraction, the dominance dimension functions quite differently. Contrast rather than assimilation is likely for the dominance dimension; interaction partners tend to differentiate in terms of dominance, and when this occurs, better relational outcomes follow.

It is important to note two relevant features of the positive experience that accompanies dominance complementarity. First, it is unlikely that participants in these studies are consciously aware that dominance complementarity or similarity exists in the relationship or are consciously aware that their enjoyment of the relationship was influenced by the existence or the lack of dominance complementarity. In Tiedens and Fragale's (2003) demonstration of people's enjoyment of nonverbal dominance complementarity, participants were queried at length about their observations of the interaction between themselves and the confederate. It was extremely rare for participants to notice any of the dominant or submissive nonverbal behavior that was expressed, and none believed that their liking of the partner or their enjoyment of the session was due to expressions of dominance and submission. Similarly, participants in the Dryer and Horowitz (1997) article described above were also not aware of the effects of complementarity on their relationship assessments. In short, the satisfaction promoted by dominance complementarity is likely unconscious. Thus, even though Americans usually endorse explicit statements about the value of equality and reject explicit statements about the value of hierarchy (Bellah, Madsen, Sullivan, Swidler, \& Tipton, 1996; Fiske, 1991), there is evidence that they nonetheless unconsciously enjoy dominance complementarity. People's desire for hierarchy could thus be an unconsciously held goal rather than an explicitly stated goal. Although it can be difficult to establish the existence of unconscious goals, there is ample evidence that unconsciously held desires affect people's behavior and cognition (Aarts et al., 2005; Chartrand \& Bargh, 1996; Chartrand \& Jefferis, 2003).

Second, support for both the emergence of dominance complementarity and the appeal of dominance complementarity comes primarily from studies in which the relationships were taskoriented. Indeed, as we have argued elsewhere, dominance complementarity may characterize only task-oriented relationships because it is in those relationships that hierarchy is most likely to provide benefits (Tiedens, Chow, \& Unzueta, 2007; Tiedens \& Jimenez, 2003). After all, hierarchies are an effective relational form for coordinating activity, allocating resources, deciding who will be responsible for what, increasing accountability, acknowledging expertise, and efficiently executing a plan (Leavitt, 2004; Weber, 1946). All of these benefits are much more relevant and useful in relationships that are task-oriented than in relationships that are purely for social connection (but, see Beach, Whitaker, Jones, \& Tesser, 2001). Thus, we assume that perceptions of dominance complementarity are most likely in task-oriented contexts. However, we do not think this diminishes their significance. 
Consider how many people one interacts with at work, how many hours one spends at work, and how important work is to one's evaluation of life (Brett \& Stroh, 2003; Greenhause, 2001; Wrzensniewski \& Dutton, 2001). Taking these things into account, understanding people's perception of their work partners is important.

\section{The Motivated Perception of Dominance Complementarity}

People desire positive relationships (Baumeister \& Leary, 1995; Maslow, 1968), and they are likely to see potential interaction partners in a way that suggests a good relationship is forthcoming (Murray, 1999). Because people are likely to have experienced the positive interpersonal outcomes associated with dominance complementarity, perceiving a potential interaction partner as complementary to oneself is a way in which people could foster optimism about an ensuing relationship. We predicted that people would engage in this pattern of perceptions. Further, we sought to provide evidence that these perceptions are the result of motivated cognition. We did this by either manipulating (Studies 2 and 6) or measuring (Studies 3 and 4) relationship motivation and by showing that perceptions of dominance complementarity are most likely when people want to be able to coordinate with another person. In doing so, we suggest that people frequently enter task-oriented relationships with an unconscious desire to produce a hierarchy in that relationship. Thus, in this work, we propose that people see others in a biased fashion; specifically, their perceptions of themselves bias their perceptions of others.

We are not alone in suggesting that self-perceptions color perceptions of others. Previous researchers have also made claims about the effects of self-perception on one's perception of others. However, the central finding in the prior work was that people project themselves onto others; that is, they see others as similar to themselves (Dunning, 2000; Krueger, 2002; Robbins \& Krueger, 2005), especially when projection helps achieve relevant goals (Maner et al., 2005). Here, we suggest a quite different way in which people's self-perceptions and goals might influence their perceptions of others. Rather than simply seeing others as similar to themselves, we argue that people see others in a way that suggests that a good relationship is forthcoming. In the case of the dominance dimension, this requires seeing the other as different from, rather than similar to, the self.

\section{Overview and Empirical Approach}

Perceptions of dominance complementarity involve both perceptions of the self and perceptions of another person (a target). Indeed, the notion of perceptions of dominance complementarity refers to a relationship between self and other perceptions. Therefore, almost all empirical work on complementarity assessed the existence of complementarity with an examination of the association between two individuals; positive correlations for the affiliation dimension and negative correlations for the dominance dimension were considered evidence of complementarity (e.g., Locke \& Sadler, 2007; Markey, Funder, \& Ozer, 2003; Sadler \& Woody, 2003). For the most part, we used this same approach to capture perceptions of dominance complementarity. In Studies $1-4$, we measured people's chronic self-perceptions on both the dominance dimension and the affiliation dimension, and we measured their perceptions of a target on both of these dimensions.
Consistent with previous literature, we consider negative correlations between self-perceived dominance and ratings of a target's dominance to constitute evidence for perceptions of dominance complementarity. In Studies 5 and 6, we manipulated self-concept and examined the resulting effects on perceptions of a target. In these studies, we were concerned with mean differences between conditions as a function of self-concept. In all the studies, we sought to show that under certain relationship conditions, differentiation or contrast occurs for the dominance dimension.

As mentioned above, these studies also provided manipulations (Studies 2 and 6) and measures (Studies 3 and 4) of goals in order to allow us to ascertain whether a motivated state underlies these perceptions. In most cases (the exception is Study 4), the context in which the measures were taken was explicitly a task-oriented one because it is in this context that complementary perceptions are most possible. In Study 4, we compared a task-oriented motivation with a socially oriented one to demonstrate that this is indeed a moderating factor.

Finally, in all of the studies, the participants were required to provide impressions of targets with whom they have had little to no contact. This is an important feature of the design, given the evidence that people tend to behave in a complementary fashion very soon after an interaction begins (Tiedens \& Fragale, 2003). As part of our argument that these perceptions are motivated (as opposed to simply accurate portrayals of the other person's behavior), we thought it was necessary to demonstrate that these perceptions appear prior to any observation of actual behavior that might provide cues to the other's personality.

\section{Study 1 \\ Method}

\section{Participants}

There were 214 people ( 88 men, 103 women, and 23 people who did not identify their sex) who participated in this study. They were recruited from an electronic mailing list that advertises studies to university affiliates. These participants signed up for a mass testing session in which they were paid $\$ 10-\$ 20$ to complete a number of tasks taking about $1 \mathrm{hr}$, in total.

\section{Materials}

Self-construal. Participants completed a shortened version of Wiggins's (1979) Interpersonal Adjective Scale (IAS). Specifically, they rated the degree to which their stable personalities could be described by the adjectives that are aligned with dominance (Scale A: Dominant; Scale I: Submissive) and affiliation (Scale M: Agreeable; Scale E: Quarrelsome). The adjectives were presented in a fixed random order. Participants were directed to rate each adjective in terms of the degree to which it describes their stable personality. These ratings were made on 7-point scales that ranged from 1 (not at all) to 7 (extremely). Composite dominant and affiliation measures were created by averaging items from the Dominant scale with the reverse of the Submissive scale items and by averaging the Agreeable scale items with the reverse of the Quarrelsome scale items. Each scale was internally reliable ( $\alpha$ for dominance $=.87, M=4.57, S D=0.83 ; \alpha$ for affiliation $=.86$, $M=5.52, S D=0.65)$. 
Table 1

Perceptions of the Experimenter Predicted by Perceptions of the Self, Study 1

\begin{tabular}{lccccc}
\hline \multicolumn{1}{c}{ Variable } & $b$ & $S E$ & $\beta$ & $t$ & $p$ \\
\hline \multicolumn{4}{c}{ Perceptions of experimenters' } \\
& & \multicolumn{2}{c}{ dominance, $F(6,182)=4.96, p<.001$} \\
Participant gender & -.10 & .07 & .10 & 1.43 & .15 \\
Experimenter Helmert code $_{1}$ & .02 & .04 & .04 & 0.51 & .61 \\
Experimenter Helmert code $_{2}$ & .20 & .08 & .18 & 2.60 & .01 \\
Experimenter Helmert code $_{3}$ & -.35 & .11 & -.22 & -3.19 & .002 \\
Self-perception of affiliation & -.12 & .11 & -.08 & -1.10 & .27 \\
Self-perception of dominance & -.26 & .08 & -.22 & -3.09 & .002 \\
\hline
\end{tabular}

Perceptions of experimenters' affiliation, $F(6,182)=4.45, p<.001$

\begin{tabular}{|c|c|c|c|c|c|}
\hline Participant gender & .01 & .07 & .01 & 0.16 & .87 \\
\hline Experimenter Helmert code $_{1}$ & .10 & .04 & .19 & 2.67 & .008 \\
\hline Experimenter Helmert code ${ }_{2}$ & .09 & .08 & .08 & 1.12 & .26 \\
\hline Experimenter Helmert code $_{3}$ & .17 & .11 & .11 & 1.52 & .13 \\
\hline Self-perception of affiliation & .41 & .11 & .27 & 3.77 & $<.001$ \\
\hline Self-perception of dominance & .14 & .09 & .11 & 1.57 & .12 \\
\hline
\end{tabular}

Note. For experimenter Helmert code $_{1}$, which compares the male experimenter to the female experimenters, the weights are $1,1,1,-3$; for experimenter Helmert $\operatorname{code}_{2}$, the weights are $1,0,1,-2$; and for experimenter Helmert $\operatorname{code}_{3}$, the weights are $1,-1,0,0$.

Perceptions of the target. In a task supposedly separate from the IAS questionnaire, participants were asked to describe the experimenter who had handed them the questionnaire packet. They were told that although they had very little information about the experimenter, they should guess what the experimenter was like. The directions indicated that the participants should write a paragraph describing what the experimenter's life was like, what the experimenter's personality was like, and what it would be like to spend time with, work with, and interact with the experimenter. Half of the page was left blank for them to write their responses.

Coding. Two people coded the paragraphs describing the experimenter. They were given the list of adjectives that comprised the Dominance, Submissive, Agreeable, and Quarrelsome scales. They were told to consider these lists of adjectives to constitute the definition of the terms dominance, submissive, agreeable, and quarrelsome. The paragraphs did not have to use any of the specific adjectives provided by the IAS in order for the coder to rate it as depicting one of the dimensions of interest. Then, the coders rated each paragraph on the degree to which the writer depicted the experimenter as dominant, submissive, agreeable, and quarrelsome, given these definitions. Ratings for each dimension were done on 7-point scales, from 1 (not at all) to 7 (extremely). The intraclass correlation (ICC) supported averaging the coders' ratings (for dominant, ICC $=.87$; for submissive, $\mathrm{ICC}=.82$; for agreeable, ICC $=.71$; and for quarrelsome, ICC $=.84$ ). The scores for submissiveness and quarrelsomeness were reversed and averaged with dominance and agreeableness.

\section{Procedure}

When participants arrived at the experiment, the experimenter asked for their name and checked that the participant was at the correct experiment at the correct time. Then, the experimenter handed the participant the questionnaire packet. That was the only interaction that the participants had with the experimenter prior to the task of describing him or her. There were three female experimenters and one male experimenter. ${ }^{1}$ Only one experimenter was present at any given session.

\section{Results}

We examined the coding of the descriptions of the experimenter using two regression analyses. In the first analysis, we investigated perceptions of the experimenter's dominance; in the second, we examined perceptions of the experimenter's affiliation. Standardized versions of both of these dependent variables were regressed on participants' self-perceptions of affiliation and dominance and on four control variables: participants' gender and three contrast codes, to capture the variance due to systematic differences in the perceptions of the four experimenters. We used Helmert contrast codes, which are a set of orthogonal codes recommended for modeling variance due to categorical variables with little theoretical importance (Judd \& McClelland, 1989). Results of these analyses are presented in Table 1 .

We predicted contrast effects for the dominance dimension and assimilation effects for the affiliation dimension, and as can be observed in Table 1, this is what we found. There were systematic differences in the degree to which the different experimenters were perceived as dominant, but controlling for those effects, selfperceptions were also related to perceptions of the experimenters' dominance. The more participants perceived themselves as dominant, the less dominant they believed the experimenter to be. This relation constitutes contrast along the dominance dimension.

The pattern was quite different for the affiliation dimension. There were, again, some systematic differences among the experimenters in terms of how affiliative they were perceived to be, and more important, there was a significant effect of self-perception. The more participants perceived themselves as affiliative, the more affiliative they perceived the experimenter. This is an assimilation

\footnotetext{
${ }^{1}$ This distribution occurred because the data were collected in mass testing sessions run by a lab for all the researchers in the school. The lab employs more women than men and is not concerned with the experimenter's gender when it runs mass testing.
} 
effect. $^{2}$ Thus, along the affiliation dimension, we observed the typical finding that people perceive a target as similar to themselves, whereas along the dominance dimension, we observed the hypothesized and novel pattern that people perceive the target as different from themselves.

\section{Discussion}

This study provided some evidence for complementary construal of others. Participants in this study demonstrated a tendency to perceive other people as complementing themselves (similar in terms of affiliation, different in terms of dominance).

This study was correlational, and it suggests that self-perceived dominance and affiliation are associated with systematic patterns in the perceptions of targets' dominance and affiliation. These associations are not simple; people do not merely see others as the same as themselves or as different from themselves. Instead, they perceive similarity between themselves and others in terms of affiliation but perceive difference in terms of dominance.

Although this study supports our claim that such perceptual patterns occur, it is silent on what the cause of these associations are. We claim that the source of these patterns is people's desire to work well with others. Because complementarity bodes well for working relationships, we posit that an expectation and desire for positive task relationships makes a complementary perception of others more likely. If we are correct, then complementary perceptions should be enhanced by contexts in which people expect to work with others and desire successful outcomes. Conversely, complementary perceptions should be attenuated in contexts in which a relationship is unlikely. We tested this possibility in Study 2 .

\section{Study 2}

If complementary construal of targets is based on people's desire to have effective task relationships with others, then this form of construal should be most likely for anticipated task partners and least likely for targets for which no relationship is expected. In this study, we tested this possibility by examining whether perceptions of targets vary depending on whether the target is an anticipated task partner or not.

\section{Method}

\section{Participants}

All components of this study were completed by 53 people ( 21 men, 32 women), in exchange for $\$ 10$. Participants were 21 years old, on average. They were recruited from an electronic mailing list that advertises studies to university community members.

\section{Materials}

There were three sets of materials: the measures of selfperceptions, the measures of target-perceptions, and the task.

Perception measures. The IAS was used to measure self- and target perceptions, and once again, the resulting scales demonstrated acceptable reliability (dominance self: $\alpha=.87$; affiliation self: $\alpha=.89$; dominance target: $\alpha=.90$; affiliation target: $\alpha=$ $.86)$.
Task. The task was called a map-making task. Participants were told that, during the session, they would be making a map of the university campus using the computer. They would accomplish this by clicking on shapes that were provided and dragging them into a work area where only the campus roads were depicted. Further, they were shown, via computer animation, that the shapes they would work with were derived from the campus map that is widely used and distributed. That is, for a short period of time, the campus map was displayed, and then, the shapes constituting that map moved off the work area into the area where all shapes rested. Thus, participants could see that each shape represented a building or some other landmark.

Some participants $(N=29)$ were told that they would be constructing the map by coordinating with another participant. They were told that their computer was networked with another participant's computer but that they would not be told which participant it was and that they would not be able to communicate directly with this person. The only information they were provided about the participant was a brief introductory statement supposedly written by the other participant. That statement read, "I am 18 years old. I come from Southern California and am an only child. I play basketball and other sports. I am a vegetarian. I go to Stanford University. I am a freshman." To increase the coordination motivation of these participants, they were also told that the pair who coordinated the best would be awarded $\$ 20$ each.

Other participants $(N=24)$ were also told about another participant and provided the same introductory statement, but they were told that this was simply another participant who was also working on the map task; in other words, they expected to work alone. They, too, were offered a $\$ 20$ reward, but in this condition, they were told the reward was based on individual performance. Both groups were asked to provide their first impressions of the other participant before beginning the map task. To enhance participants' belief that another participant actually wrote the introductory statement, all participants had been asked to provide a short descriptive statement suitable for introducing themselves to another participant and were told that the other participant was simultaneously reading the statement they wrote.

Procedure. The self-perception measure was administered in an online prescreening session and appeared among a number of other questionnaires that were not related to this study. Many weeks later, all participants who filled out the online survey were invited to come to the lab for another study. The participants had no knowledge that the invitation was extended only to those who filled out the previous online survey or that the current study was in any way related to the questionnaire they had completed online.

\footnotetext{
${ }^{2}$ We also ran more complicated models in which we examined the interaction between experimenter and participant sex. An interaction between a four-level experimenter factor and participant sex was nonsignificant for perceptions of the experimenters' dominance and affiliation. An interaction between the contrast code comparing the male experimenter to the female experimenters and participant sex was not significant for perceptions of the experimenters' affiliation and was marginally significant for perceptions of the experimenters' dominance $(p=.10)$. Exploratory follow-up analyses suggested that this marginal interaction was due to negative associations between self- and other perceptions in all gender pairings; however, this association was weakest among male participants rating a male experimenter. This pattern is not replicated in any other study in this series.
} 
After checking in at the lab, participants were seated at computers in cubicles. They provided an introductory statement about themselves; then, they read the instructions for the map-making task; next, they saw the introductory statement from the "other participant;" and finally they rated their first impressions of the other participant with IAS items.

\section{Results and Discussion}

To test whether complementary perceptions of others are more likely about targets with whom the individual expects to work, we ran two regressions - one in which we examined the perceptions of the targets' dominance and another in which we examined perceptions of the targets' affiliation. In both models, the predictors were participant sex, self-perceived affiliation, self-perceived dominance, the expectation to coordinate with the target or to work alone, the interaction of work expectation with self-perceived affiliation, and the interaction of work expectation with selfperceived dominance.

In the model predicting perceptions of target dominance, the only significant effect was the hypothesized one associated with the interaction of work expectation and self-perceived dominance $(\beta=-.38), t(46)=-2.83, p<.01$. We decomposed this interaction following the methods recommended by Aiken and West (1991). The slopes are displayed in Figure 1 and illustrate that among participants who expected to coordinate with the target, there was the predicted negative relationship between selfperceived dominance and perceptions of the target's dominance, $(\beta=-.34), t(46)=1.98, p=.053$. In the work alone condition, participants perceived the target to be similar to themselves, $(\beta=$ $.41), t(46)=2.03, p<.05$.

Among participants who expected to coordinate with the target, we had expected to observe a positive relationship between participants' self-perceived affiliation and their perceptions of the target's affiliation. However, there were no significant effects in the model predicting perceptions of targets' affiliation. An explanation for this null effect may be that because the interaction was going to be over the computer, participants did not think that interpersonal warmth was relevant to success on the task (Moore, Kurtzberg, Thompson, \& Morris, 1999).

Thus, in this study, when participants believed they were going to work with another participant, they perceived that person to be dom-

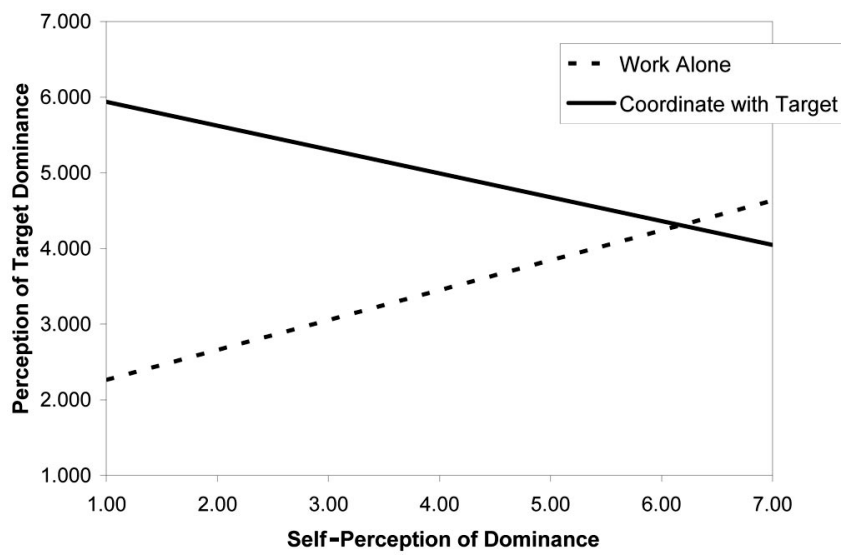

Figure 1. Estimated perceptions of the target in Study 2. inance complementary with themselves. We argue that in this condition, the participants had reason to want a good working relationship with the target, and it is only when such a desire exists that dominance complementary perceptions occur. When participants believed that the other participant was merely going to do the task at the same time, they did not engage in this perceptual pattern. Instead, they appeared to simply think of the other participant as similar to themselves, similar to findings about projection (Krueger, 2002; Robbins \& Krueger, 2005). The difference between these two conditions lends support to the notion that perceptions of dominance complementarity are the result of motivation.

\section{Study 3}

In Study 2, we argued that, in certain situations, people's desire for a good relationship is heightened (for example when working with another person leads to rewards) and that in these situations perceptions of dominance complementarity should be increased. And, we showed evidence of that effect. However, the desire to work effectively with others is not just determined by situations, it also varies from individual to individual. A project of greatest importance to one individual might be a low priority for another. Indeed, these differences in motivation are one reason why coordinated work can be so difficult (Hackman \& Suttle, 1977). If perceptions of dominance complementarity are a result of this motive, then variance in individual desire for successful work relationships should correspond to variation in perceptions of dominance complementarity. Specifically, our approach suggests that those people with the greatest desire for the task to go well will be most likely to engage in perceptions of dominance complementarity. We examined this hypothesis in Study 3.

\section{Method}

\section{Participants}

Participants were recruited from an intensive, month-long summer program on business management at a west coast university. There were 141 students who were enrolled in the program. Of these, 96 students filled out the two waves of questionnaires necessary for this study. Of these participants, 1 who did not follow the directions was excluded from analyses. Our final sample of 95 was comprised of 49 male and 46 female participants. Their average age was 22 years, and they were generally Caucasian/White $(n=60)$, however some other ethnicities were represented as well (5 described themselves as Hispanic/Latino, 21 described themselves as Asian/Asian-American/ Pacific Islander, 2 described themselves as African American/Black, and 7 did not identify themselves). Participation in the study was purely voluntary.

\section{Materials and Procedure}

Participants filled out questionnaires at two points in time. The first questionnaire was handed out in a sealed envelope during the 1st week of the program. Students were asked to fill out the questionnaire in the evening when they were alone and to return it the following day. This questionnaire required participants to rate a specific other student in the program (the target). They were all assigned to rate a same-sex student who was a member of their study group. Students had learned what other students were in their study group on the previous day. They had been informed that they 
would be working with their study group on a number of assignments for several different classes (e.g., accounting, finance). In the questionnaire, they were asked to rate the target on IAS following the same format as in prior studies. The questionnaire also included a question about their desire for their study group to succeed. Specifically, they were asked, "How important to you is it that your study group succeeds?" They rated this on a 7-point scale that ranged from 1 (not at all) to 7 (extremely). From here on, we refer to this item as the motivation item.

The second questionnaire was done on the Internet. During the beginning of the last week of the month-long course, participants received an e-mail with a link to a website that contained the final questionnaire. On this questionnaire, participants rated their stable personalities on the IAS items.

We provided an explanation of the study for interested parties at the end of the program.

\section{Results and Discussion}

Composite variables for self-perceived dominance $(\alpha=.71$, $M=4.84, S D=0.71)$, self perceived affiliation $(\alpha=.69, M=$ $5.53, S D=0.57)$, perception of target dominance $(\alpha=.80, M=$ $4.58, S D=0.80)$, and perception of target affiliation $(\alpha=.91$, $M=6.11, S D=0.67)$ were created.

Perceptions of target dominance were regressed on the selfperception items, the motivation item, and the interactions between the motivation item and the self-perception items. We also included sex and class section as control variables. We predicted that the interaction between motivation and self-perceived dominance would be significant and would be due to highly motivated individuals being particularly prone to perceptions of dominance complementarity. The only significant effect in this model was the interaction between motive and self-perceptions of dominance $(\beta=-.30), t(87)=2.52, p<.05$. We probed this interaction following the procedures of Aiken and West (1991). As illustrated in Figure 2, the simple slope for participants who are 1 standard deviation higher than the mean for motivation is significantly negative $(\beta=-.46), t(87)=-2.13, p<.05$. Although the slope for people 1 standard deviation below the mean for motivation looks slightly positive, this slope is not different from $0(\beta=.25)$, $t(87)=1.25$. Thus, these results demonstrate that perceptions of dominance complementarity are more likely among people who really want the working relationship to be successful.

We did a similar analysis on perception of the target's affiliation. The only significant results in this analysis were a main effect

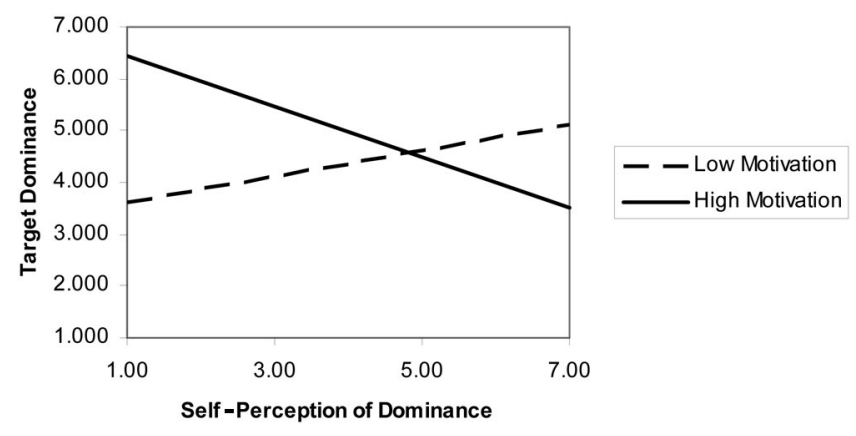

Figure 2. Perceptions of a study group partner in Study 3. for sex, such that women perceived their female targets as more affiliative $(\beta=.24, p<.05)$ and a main effect for self-perception of affiliation $(\beta=.34, p<.05)$.

Thus, this study provides further evidence that perceptions of dominance complementarity are a function of the desire for a successful working relationship.

\section{Study 4}

In the previous two studies, we provided some evidence that perceiving dominance complementarity is a function of one's motivation to have a good relationship with the target. When one is more motivated, perceiving dominance complementarity is more likely. In the previous studies, the relationship was situationally defined as a task-oriented one. Thus, motivation for a good relationship was equivalent to the desire to work well together on a task. Many relationships, however, are more complex in that there are numerous ways in which individuals can construe the relationship and, thus, numerous goals they can hold for the relationship. For example, one can conceptualize a new colleague as a potential collaborator or as a potential friend. One's perceptions of, evaluations of, and behavior toward this colleague will vary depending on whether one is more concerned about coordinating research efforts or socializing. Our approach suggests that the goals one holds for the relationship should have important effects on the perception of dominance complementarity. Namely, because we believe that perceptions of dominance complementarity are an instance of motivated perception in which the underlying motivation is the desire to coordinate well on tasks, we hypothesize that it is only when people prioritize this goal in a particular relationship that they will engage in dominance complementary construal.

In Study 4, we tested this hypothesis by examining new college students' perceptions of their roommates. Like many social relationships, the roommate relationship can be conceptualized in many ways, and there is likely to be natural variation in the goals individuals have for the relationship. Some people will prioritize the coordination aspect of living together, whereas others may prioritize the potential for a close friendship. In this study, we expected to find that only those who prioritized the goal of coordination would engage in perceptions of dominance complementarity.

\section{Method}

\section{Participants}

Participants in this study were 98 first-year college students (59 men and 39 women). They were recruited from the dining halls of freshman dormitories by an experimenter who asked them whether they would be willing to fill out a short questionnaire in exchange for a candy bar. The participants were approached during the 1 st week of classes. Of the participants, 3 (1 woman and $2 \mathrm{men}$ ) did not provide ratings of their roommates and, thus, could not be included in the analyses. We also excluded 1 participant who, in the margins, wrote notes that suggested that he was not taking the questionnaire seriously.

\section{Materials}

The questionnaire consisted of three parts: self-perception ratings, questions about goals for the roommate relationship, and perceptions of the roommate's personalities. The self-perception 
ratings and the perception of the roommate's personality ratings consisted of adjectives from the IAS. These scales were, once again, reliable (self dominance: $\alpha=.81, M=4.34, S D=0.86$; self affiliation: $\alpha=.86 M=5.55, S D=0.70$; roommate dominance: $\alpha=.81, M=4.47, S D=0.74$; roommate affiliation: $\alpha=$ $.92, M=5.69, S D=0.99$ ).

In the section on goals and motives, we wanted to distinguish between students who prioritized succeeding at the task component of the roommate relationship (and, thus, had the goal of coordinating with their roommate) from those who did not prioritize this goal. Therefore, we measured the degree to which people were seeking coordination with their roommate with two items: "How important to you is it for you and your roommate to come up with rules or guidelines that will make living together peaceful?" and "How important is it for you to have a similar waking/sleeping schedule as your roommate?' In order to assess the degree to which these goals were a priority over other goals, we also measured the degree to which participants were seeking a close friendship with their roommate. Our items to measure the degree to which people were seeking friendship in their roommate relationships were, "How important to you is it for your roommate to include you in social events he/she attends?" and "How important to you is it for your roommate to tell you about his/her personal life?" All of the goal items were rated on scales that ranged from 1 (not important at all) to 7 (extremely important). We hypothesized that people who were more concerned with coordination than friendship would engage in complementary construal.

\section{Results}

First, we categorized participants into two groups: those who prioritized coordination (i.e., rated the coordination items higher than the friendship items in one group; $N=55$ ) and those who did not prioritize coordination $(N=39)$.

Next, we examined the relationship between self-perceptions and other perceptions. In the first analysis, we regressed the perceptions of the roommates' dominance on the participant's sex, the participant's self-perceptions of affiliation and dominance, the goal priority, and the interactions between goal priority and selfperceptions. In the second regression, perceptions of roommates' affiliation were regressed on the same independent variables.

In the analysis predicting perceptions of the roommates' dominance, there was only one significant effect: the hypothesized interaction between self-perceptions of dominance and goal priority $(b=-.33, \beta=-.28), t(87)=2.75, p<.01$. The decomposed interaction is presented in Figure 3; it demonstrates the predicted negative relationship between self-perceptions of dominance and perceptions of roommate's dominance among people who prioritized coordination, $(b=-.31, \beta=-.27), t(87)=2.04, p<.05$. Among people who did not prioritize coordination, there was a marginally positive relationship between self-perceived dominance and perception of roommate's dominance $(b=.35, \beta=.31)$, $t(87)=1.87, p<.10$.

In the analysis predicting perceptions of roommates' affiliation, there was only one significant effect; a main effect for selfperception of affiliation $(b=.49, \beta=.34), t(87)=3.31, p<.01$. Thus, regardless of goal priority, we observed an assimilation effect for perceptions of affiliation.

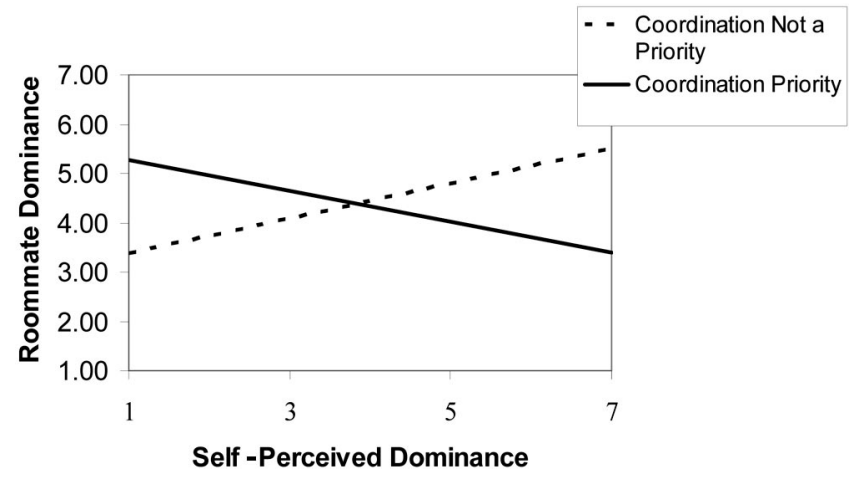

Figure 3. Perceptions of a new roommate in Study 4.

Study 5

People have stable and chronic ways of characterizing themselves, and these were measured and examined in the previous studies. However, there are also transient self-perceptions that are shaped by salient situational features and experiences. Markus and Wurf (1987) called these situationally activated self-perceptions "the working self-concept" and argued that they affect information processing and social perception-a claim that has been wellsupported in the empirical research (see Hoyle, Kernis, Leary, \& Baldwin, 1999).

If construing others in a way that is complementary to the self is due to the desire to work well with a target, then this kind of effect should occur not only for chronic self-perceptions (as shown in Studies 1-4) but also for transient self-perceptions. The effects we have already demonstrated rely on chronic self-perceptions and can be interpreted as evidence of chronic perceptions of others (at least, chronic perceptions in particular situations or when particular goals are relevant). If the same patterns are observed in response to the transient, working self-concept, it provides more evidence that these perceptions of others can fulfill a more immediate function or goal for the individual. Furthermore, such effects would make the causality of these patterns more clear. Therefore, in this study, we influenced the way in which participants perceived themselves and then measured their perceptions of a target whom they imagined working with.

\section{Method}

In this study, we used a similar method to that of Study 1. An experimenter in a mass testing session was the target about whom participants reported their perceptions. The differences between this study and Study 1 were that (a) in this study, prior to reporting their perceptions of the experimenter, the participants completed a task intended to influence their self-perception and that (b) in this study, instead of providing open-ended descriptions of the experimenter as they had in Study 1, the participants rated the experimenter on trait adjectives from the IAS.

\section{Participants}

In this study, there were 292 (132 male, 138 female, and 22 unidentified) participants. Their average age was 20 years. They were recruited from the electronic mailing list described in prior studies for a mass testing session in which they would complete a 
number of questionnaire studies in exchange for \$20. The testing session was approximately $1 \mathrm{hr}$ in length. The materials for this study were interspersed among a number of questionnaires unrelated to this study.

\section{Materials and Procedure}

Self-perception manipulation. In the first component of this study, participants completed a task intended to influence their self-perceptions. Specifically, all participants were asked to list four instances from their lives in which they acted in a particular manner. Participants in the dominant condition $(n=83)$ were asked to describe four instances in which they felt self-confident and acted in an assertive and directive manner; participants in the submissive condition $(n=70)$ described four instances in which they felt timid and followed someone else's directions; participants in the agreeable condition $(n=76)$ listed instances in which they felt friendly and acted in a warm and polite manner; and the final group, the quarrelsome condition, $(n=63)$ listed instances in which they felt unfriendly and acted in a cool and distant manner. These directions were intended to induce self-perceptions of dominance, submissiveness, agreeableness, or quarrelsomeness, respectively.

Perceptions of the experimenter. Next, participants were asked to imagine working on a class project with the experimenter and to write a paragraph describing what they think the experimenter would be like in that context. One male experimenter was rated by all participants. This was followed by a questionnaire on which the participants rated the experimenter on the IAS items measuring dominance and affiliation. These ratings were once again made on 1-7 scales. Once again, the items were averaged into reliable scales (affiliation: $\alpha=$ .92; dominance: $\alpha=.87$ ).

Manipulation checks. Finally, participants rated themselves on 4 adjectives: dominant, self-assured, kind, and welcoming, on 1 to 7 scales. The first two ratings were averaged and used as a manipulation check for the dominant and submissive conditions, and the second two were averaged and used as a manipulation check for the agreeable and quarrelsome conditions.

\section{Results and Discussion}

We first looked through all the questionnaires and found that 37 people (12.7\% of the participants) had not completed the selfdescription manipulation ( 7 in the dominant conditions, 17 in the submissive condition, 4 in the agreeable condition, and 9 in the quarrelsome condition). These individuals either had written nothing or had listed fewer than 4 instances in which they had behaved in the manner consistent with their condition. Because of concerns that these participants' self-concept would not have been influenced in the intended manner (Schwarz et al., 1991), we excluded these participants from the analyses.

\section{Manipulation Checks}

One-way analyses of variance (ANOVAs) were conducted on the two manipulation check variables. The omnibus tests were not statistically significant $\left(F_{\mathrm{S}}<2\right)$, but the relevant contrasts indicated that, in fact, the manipulation was successful. Participants who wrote about instances in which they behaved in a dominant fashion rated themselves as more dominant $(M=4.71, S D=1.05)$ than did those who wrote about instances in which they behaved in a submissive way $(M=4.28, S D=1.11), t(251)=2.07, p<.05$, $\eta_{\mathrm{p}}{ }^{2}=.02$. Participants who wrote about instances in which they acted in an agreeable way rated themselves as more agreeable $(M=5.46, S D=0.95)$ than did those who wrote about times when they behaved in a quarrelsome fashion $(M=5.12, S D=1.05)$, $t(251)=2.04, p<.05, \eta_{\mathrm{p}}{ }^{2}=.02$.

\section{Perceptions of the Experimenter}

We also examined perceptions of the experimenter with one-way ANOVAs. Once again, the omnibus tests were not significant, but the planned contrasts provided evidence that people perceived the experimenter as complementary to their induced self-concept. People who wrote about times in which they behaved in a dominant way rated the experimenter as less dominant $(M=4.42, S D=0.90)$ than did people who wrote about times in which they behaved in a submissive way $(M=4.71, S D=0.61), t(251)=2.05, p<.05, \eta_{\mathrm{p}}{ }^{2}=.02$. People who wrote about instances in which they were agreeable perceived the experimenter as more agreeable $(M=5.23, S D=0.77)$ than did those who wrote about quarrelsome instances $(M=4.94, S D=0.80)$ $t(251)=2.00, p<.05, \eta_{\mathrm{p}}{ }^{2}=.02$.

Finally, we also examined the relationships between selfperception and perceptions of the experimenter by looking at associations between the manipulation check measures and the perceptions of the experimenter measures. We ran two regression analyses: one in which self-perceptions of dominance and affiliation and participant sex were used to predict the person's perceptions of the experimenter's dominance and one in which these same independent variables were used to predict perceptions of the experimenter's affiliation. In the regression predicting perceptions of dominance, the only significant effect was the predicted one that was associated with self-perception of dominance $(b=-.10, \beta=-.14), t(231)=2.17, p<.05$. In the analyses predicting perceptions of affiliation, the only significant effect was for self-perceptions of affiliation, which was positively related to perceptions of the experimenter's affiliation $(b=.26, \beta=.30), t(231)=4.75, p<.05 .^{3}$

In sum, this experiment shows that people engage in the complementary perception of others, and people do so not just when they rely on a chronic perception of themselves or chronic ways of perceiving others. Instead, people seem to tune their perceptions of others to create complementarity, depending on how they are temporarily feeling about themselves.

\section{Study 6}

In the final study, we manipulated both participants' temporary perceptions of themselves and their beliefs about a potential future relationship. Consistent with the previous studies, we hypothesized that participants would perceive another individual to be complementary to their temporarily activated self-perception when they

\footnotetext{
${ }^{3}$ We also ran these analyses with the full data set (including the people we excluded because they did not complete the manipulation). In the regression examining perceptions of experimenter's dominance, the only significant predictor was the self-perceptions of dominance $(b=-.10, b=$ $-.14), t(265)=2.39, p<.05$. Self-perceptions of affiliation was the only variable that significantly predicted perceptions of experimenter's affiliation $(b=.25, b=.29), t(265)=4.91, p<.001$.
} 
expected to do a task with that individual but that they would not do so when no relationship was possible. In this study, we focused solely on perceptions of dominance and submission both because we wanted to keep the size of the study reasonable and because the hypothesized contrast effects associated with this dimension are the more novel hypotheses (i.e., they do not fit the assimilative pattern demonstrated in prior research).

\section{Method}

\section{Participants}

In this study, 204 people (80 men and 124 women) participated in exchange for $\$ 10$. They were recruited from an electronic mailing list that advertises the opportunity to participate in studies to interested parties. These participants responded to an advertisement for two studies on interpersonal dynamics and first impressions. Participants were run in groups of 4 to 8 ; however, upon arriving at the laboratory, they were sent to one of three computer rooms, where they completed the entire study sitting at small cubicles.

\section{Procedure and Materials}

Self-concept manipulation. After filling out a consent form, participants completed the materials for the self-concept manipulation. The materials were described as a study on interpersonal dynamics. Participants were asked to list six instances in which they acted in either a self-assured way $(n=108)$ or a self-doubting way $(n=96)$.

Relationship manipulation. After finishing the self-concept manipulation, participants completed what they were told was the next study, which was done on the computer. Participants were told that this was a study about first impressions and that they would be asked to give their first impressions of another person, whose picture would be provided. Some of the participants were told that the person they would see was a student at another university $(n=94)$. Other participants were told that the person they would see was another participant in the study who was sitting in a different computer room and that they would be working with this person on another task later in the session $(n=$ 110). ${ }^{4}$ To make this more believable, participants were told that while they had been sitting at the computer, their picture was taken by the webcam located on the computer and that their picture would simultaneously be shown to the other participant. In reality, we did not take pictures of the participants. To further reinforce the manipulation, participants in the future interaction condition were asked to guess what kind of task they would work on with the other person later in the session, and participants in the no future interaction condition were asked to guess what university the other person attended.

The participants were then shown the picture of the other participants. There was one picture of a woman and one picture of a man. Female participants were exposed to the picture of a woman and male participants were exposed to the picture of a man. The picture was shown for $10 \mathrm{~s}$ and then the participants were asked to rate the target.

Measures. Participants rated the target on eight adjectives, which were taken from the Wiggins' (1979) IAS scale (dominant, assertive, domineering, forceful, submissive, unbold, meek, and unaggressive). Each rating was made on a scale that ranged from 1 (not at all) to 7 (extremely). The last four adjectives were reversed and then all 8 ratings were averaged $(\alpha=.80)$.

At the end of the session participants answered manipulation checks for the self-concept manipulation. Specifically, participants rated the degree to which they themselves are firm and timid (reversed). These ratings were on the same 7-point scales and were averaged to constitute the self-concept manipulation check.

\section{Results}

\section{Manipulation Checks}

First, we examined the records from the self-concept manipulation. We found that 6 people did not complete the manipulation ( 3 in the dominant condition and 3 in the submissive condition). These people were excluded because of a concern that those who had difficulty responding to this task would conclude that the target trait was not at all descriptive of themselves (Schwarz et al., 1991). We also examined the open-ended responses of participants who were asked to guess what task they would work on with the other person. Of these, 6 people wrote some variant of not believing that the other person existed or not believing that there would be a task. These people were also excluded from the remaining analyses.

The remaining self-ratings were examined with a 2 Sex (male vs. female) $\times 2$ Self-Concept (dominant vs. submissive) ANOVA and suggested that the self-concept manipulation had been successful. Participants who wrote about six times in which they behaved in a self-assured way rated themselves as more dominant $(M=4.75, S D=1.12)$ than participants who wrote about six times in which they behaved in a self-doubting way $(M=4.44$, $S D=0.98), F(1,188)=4.10, p<.05, \eta_{\mathrm{p}}{ }^{2}=.02$. There were no effects due to sex of the participant.

\section{Ratings of the Picture}

The ratings of the target were examined with a 2 Sex (male vs. female) $\times 2$ Relationship (anticipated relationship vs. no anticipated relationship) $\times 2$ Self-Concept (dominant vs. submissive) ANOVA. There were only two significant effects in this analysis. There was a main effect for the sex of the participant, $F(1,184)=$ $7.62, p<.01$, which was due to women rating the picture that they saw as more dominant $(M=4.13, S D=0.77)$ than men rated the picture that they saw $(M=3.80, S D=0.77)$.

More important for our hypotheses, there was also a significant interaction between relationship and self-concept, $F(1,184)=$ 4.62, $p<.05, \eta_{\mathrm{p}}{ }^{2}=.02$. Planned paired comparisons revealed that this interaction showed the expected pattern. Specifically, within the anticipated relationship condition, self-concept had a significant effect. Within the anticipated relationship condition, submissive participants perceived their future relationship partner to be more dominant $(M=4.17, S D=0.70)$ than dominant participants

\footnotetext{
${ }^{4}$ This also implied that the target was from the same university as the participants. Note that this makes this a particularly challenging test of our hypotheses, given prior findings that show projection or assimilation is most likely for ingroup members, whereas contrast is more likely for outgroup members (Clement \& Krueger, 2002). Thus, previous literature would expect the exact opposite pattern from the one we predict.
} 
$\operatorname{did}(M=3.82, S D=0.77), t(188)=2.20, p<.05, \eta_{\mathrm{p}}{ }^{2}=.02$. Within the no future relationship condition, there was no difference in the way that dominant $(M=4.05, S D=0.77)$ and submissive $(M=3.97, S D=0.88), t(188)<.5$ participants perceived the student from another university. Thus, only when people believed they would be interacting with the person pictured did they perceive the person to be complementary in terms of dominance to their own induced self-perception.

\section{General Discussion}

These studies provide evidence that people tend to see potential task partners in a dominance complementary fashion. The tendency to perceive a difference between the self and others for dominance is enhanced to the degree that people want a successful work relationship with the target. This moderator supports the idea that complementary perceptions of others are a case of optimistic relational perceptions. People often desire good work relationships and they see anticipated work partners in a way that suggests they will work well together.

\section{Assimilation for Affiliation and Contrast for Control}

This research is not the first to show that people perceive relationship partners differently from how they perceive nonrelationship partners. Indeed, quite a few studies in the literature on contrast and assimilation effects have shown a difference between these two kinds of targets. However, in that literature, the conclusion has been that relational targets are even more likely to be associated with assimilation effects, or projection, than nonrelational targets (Robbins \& Krueger, 2005; Miller \& Marks, 1982; Murray et al., 1996), and this is assumed to generalize to any dimension of judgment. In this research, we have shown that assimilating a relationship partner to the self can occur for the affiliation dimension but that contrast occurs for the control dimension when a successful task relationship is expected or desired. Thus, there is nothing sacred about the association between relational partners and assimilation. Instead, assimilation and contrast can both occur, and their occurrence depends on the judgment dimension (dominance versus affiliation) and the goals for the relationship. Other research on the optimistic perceptions people hold for interaction partners has demonstrated the flattering notions people hold about their relationship partners. Although we also argue that people perceive potential relationship partners in an optimistic way, we suggest that such perceptions need not be so flattering about the individual. In these studies, participants sometimes saw their future relationship partners as less dominant and more submissive, a profile that previous research has shown to be considered negative (Locke, 2003; Stapel \& Van der Zee, 2006; Tiedens \& Jimenez, 2003). There are some negative characteristics that portend a positive relationship, and we found that our participants were willing to see these attributes in targets with whom they anticipated needing to work on a task.

\section{Optimism About Relationships}

Our hypotheses about assimilation for affiliation and contrast for control were based on interpersonal theory and the notion of complementarity. Interpersonal theorists have suggested that difference rather than similarity in terms of dominance and submis- sion is associated with relationship success. When this form of complementarity has been examined, it has, in fact, been shown to be associated with relationship satisfaction (Dryer \& Horowitz, 1997; Tiedens \& Fragale, 2003). This hypothesis is surprising in two ways. First, the received wisdom in social psychology is about the benefits of similarity between relationship partners. Neither we nor interpersonal theorists dispute the large literature that demonstrates those effects. Similarity on many dimensions is good for relationships; however, the dominance dimension functions differently than those other dimensions.

That the difference on the dominance dimension is beneficial may also be surprising because it suggests that hierarchical differentiation is preferable to equality in interpersonal interactions. At least in the United States, our cultural ideology promotes the notion that equality is better and more enjoyable than hierarchical differentiation (Bellah et al., 1996; de Tocqueville, 1862/1969). And indeed, when people were explicitly asked about positive and negative aspects of relationships, equality was mentioned as a positive attribute and situations in which one person was dominant and another was submissive were considered problematic (Van Lange et al., 1997). We doubt that many people in the United States would explicitly say that they desire a relationship partner who is more dominant or more submissive than they themselves are, and they would not say that their ideal relationship is a hierarchical one. However, the preference for and enjoyment of complementarity may be unconscious (Tiedens \& Fragale, 2003). The results demonstrated in this article may depend on the participants being largely unaware of the relationship between their self-perceptions and their perceptions of a future interaction partner. One methodological difference between this work and other work that has examined how perception of relationship partners reflect respondent ideals is that prior work has always required participants to explicitly state their ideals (e.g., LaPrelle, Hoyle, Insko, \& Bernthal, 1990; Murray et al., 1996). That kind of methodology might obscure dominance complementarity, which may be rejected at the conscious level. Of course, we did not compare implicit and explicit relationship ideals, but an investigation of this would be an interesting avenue for future research.

Another difference between our approach and the research that has emphasized assimilative and flattering perceptions of relationship partners is that prior work has been concerned primarily with social relationships (LaPrelle et al., 1990; Murray \& Holmes, 1997; Murray et al., 1996; Thomas, Fletcher, \& Lange, 1997), whereas this work, and much of the research on complementarity, has been concerned with task-oriented relationships. Although in some of the research on the benefits of similarity, researchers have examined coworkers (e.g., Glaman, Jones, \& Rozelle, 2002), the dominance dimension has typically not been examined, and it is only on this dimension that the benefits of contrast might occur. Elsewhere, we have provided evidence that contrast on the dominance dimension is more likely in task relationships than in purely social or affiliative ones (Tiedens \& Jimenez, 2003), and the results from Study 4 suggest that this is the case. We think that the current state of the relationships literature has downplayed the importance of relationships with work partners and that the current literature may have overemphasized people's affiliation goals in their social relationships and may have underemphasized their coordination goals. For example, although roommate studies are often concerned with the friendship component of the relationship, more of our participants prioritized coordination with their room- 
mate than affiliation. This may also be true in marriages and in other relationships in which partners who affiliate also need to coordinate on any number of tasks. Such relationships may entail more dominance complementarity than might be expected if we viewed these relationships as purely affiliative (Beach, Witaker, Jones, \& Tesser, 2001). An examination of work relationships and coordination goals is not only important because they are a central part of people's lives, but also, in this case, because an examination of them shows that optimism can take forms other than assimilation and flattery.

With an examination of the perceptions of task partners, these findings also shed light on the psychological processes through which social hierarchies come to exist. In this research, it appears that when people enter a task-oriented relationship, they do so with an unconscious desire for and expectation of hierarchical differentiation. Given the powerful role of expectations on social behavior (Darley \& Fazio, 1980; Olson, Roese, \& Zanna, 1996), these perceptions lay the ground for the emergence of hierarchical differentiation between task partners, even when no formal hierarchy may exist. That people tend to express dominance complementarity in their behavior (Tiedens \& Fragale, 2003) suggests that these initial perceptions could be combined with actual behavior in a way that seals hierarchical differentiation in place. In this way, the findings presented in this article speak to the psychology of the frequently noted, but largely unexplained, phenomenon of the spontaneous emergence of hierarchies in work groups (Forsyth, 1983). Although we acknowledge that the size of the effects we uncovered was not always large, we see these effects as having the potential to begin a cycle that leads to the emergence of interpersonal hierarchies in task groups and teams.

\section{Conclusions}

Whenever patterns in social perception emerge that are not well-justified by objective features of the target, the question of whether they ought to be normatively condemned are soon to follow. Clearly, the effects demonstrated in these studies are not the result of objective evaluation, but that does not mean they are necessarily dysfunctional. Murray and her colleagues (Murray et al., 1996, 1999) argued that sometimes self-deception and optimism about future relationship partners can be useful. Positive relational expectancies can put a positive cycle in place, and given that positive relationships fulfill a basic human need, this may be a bias that may increase the well-being of those who fall prey to it. To the extent that complementarity promotes good relationships, we can then see this phenomenon as functional. At the same time, these perceptions could prematurely create hierarchical differentiation, which may be unnecessary for successful completion of the task. Or, given the speed with which these perceptions occur, it may be that the produced hierarchy is incorrect for the context, with the wrong person dominating another. Thus, we think it is too early to say whether these perceptual patterns are adaptive or dysfunctional. For now, what is evident is that people perceive potential task partners as complementary to themselves.

\section{References}

Aarts, H., Chartrand, T. L., Custers, R., Danner, U., Dik, G., Jefferis, V. E., et al. (2005). Social stereotypes and automatic goal pursuit. Social Cognition, 23, 465-490.
Aiken, L. S., \& West, S. G. (1991). Multiple regression: Testing and interpreting interaction. Thousand Oaks, CA: Sage.

Baumeister, R. F., \& Leary, M. R. (1995). The need to belong: Desire for interpersonal attachments as a fundamental human motivation. Psychological Bulletin, 117, 497-529.

Beach, S. R., Whitaker, D. J., Jones, D. J., \& Tesser, A. (2001). When does performance feedback prompt complementarity in romantic relationships? Personal Relationships, 8, 231-248.

Bellah, R. N., Madsen, R., Sullivan, W. M., Swidler, A., \& Tipton, S. M. (1996). Habits of the heart: Individualism and commitment in American life. Berkeley, CA: University of California Press.

Berscheid, E., Brothen, T., \& Graziano, W. (1976). Gain-loss theory and the "law of infidelity": Mr. Doting versus the admiring stranger. Journal of Personality and Social Psychology, 33, 709-718.

Brett, J. M., \& Stroh, L. K. (2003). Working 61 plus hours a week: Why do managers do it? Journal of Applied Psychology, 88, 67-78.

Byrne, D. (1971). The attraction paradigm. New York: Academic Press.

Byrne, D. (1997). An overview (and underview) of research and theory within the attraction paradigm. Journal of Social and Personal Relationships, 14, 417-431.

Carson, R. C. (1969). Interaction concepts of personality. Chicago: Aldine Publishing.

Chartrand, T. L., \& Bargh, J. A. (1996). Automatic activation of impression formation and memorization goals: Nonconscious goal priming reproduces effects of explicit task instructions. Journal of Personality and Social Psychology, 71, 464-478.

Chartrand, T. L., \& Jefferis, V. E. (2003). Consequences of automatic goal pursuit and the case of nonconscious mimicry. In J. P. Forgas, K. D. Williams, \& W. von Hippel (Eds.), Social judgments: Implicit and explicit processes (pp. 290-305). New York: Cambridge University Press.

Clement, R. W., \& Krueger, J. (2002). Social categorization moderates social projection. Journal of Experimental Social Psychology, 38, 219231.

Darley, J. M., \& Berscheid, E. (1967). Increased liking as a result of the anticipation of personal contact. Human Relations, 20, 29-40.

Darley, J. M., \& Fazio, R. H. (1980). Expectancy confirmation processes arising in the social interaction sequence. American Psychologist, 35, $867-881$.

de Tocqueville, A. (1969). Democracy in America (G. Lawrence, Trans.). Garden City, NY: Doubleday. (Original work published 1862)

Dryer, D. C., \& Horowitz, L. M. (1997). When do opposites attract? Interpersonal complementarity versus similarity. Journal of Personality and Social Psychology, 72, 592-603.

Dunning, D. (2000). Social judgment as implicit social comparison. In J. Suls \& L. Wheeler (Eds.), Handbook of social comparison: Theory and research (pp. 353-378). Dordrecht, the Netherlands: Kluwer Academic.

Dunning, D., Meyerowitz, J. A., \& Holzberg, A. D. (1989). Ambiguity and self-evaluation: The role of idiosyncratic trait definitions in self-serving assessments of ability. Journal of Personality and Social Psychology, 57, 1082-1090.

Fiske, A. P. (1991). Structures of social life: The four elementary forms of human relations. New York: Free Press.

Forsyth, D. R. (1983). An introduction to group dynamics. Belmont, CA: Brooks/Cole.

Glaman, J. M., Jones, A. P., \& Rozelle, R. M. (2002). Competitiveness and the similarity of preferred coworkers. Journal of Applied Social Psychology, 32, 142-158.

Greenhause, S. (2001). Report shows Americans have more 'Labor Days.' The New York Times, p. A6.

Hackman, J. R., \& Suttle, J. L. (1977). Improving life at work. Santa Monica, CA: Goodyear.

Horowitz, L. M., Dryer, D. C., \& Krasnoperova, E. N. (1997). The circumplex structure of interpersonal problems. In R. Plutchik \& H. R. 
Conte (Eds.), Circumplex models of personality and emotions (pp. 347-384). Washington DC: American Psychological Association.

Horowitz, L. M., Wilson, K. R., Turan, B., Zolotsev, P., Constantino, M. J., $\&$ Henderson, L. (2006). How interpersonal motives clarify the meaning of interpersonal behavior: A revised circumplex model. Personality and Social Psychology Review, 10, 67-86.

Hoyle, R. H., Kernis, M. H., Leary, M. R., \& Baldwin, M. W. (1999). Selfhood: Identity, esteem, regulation. Boulder, CO: Westview Press.

Judd, C. M., \& McClelland, G. H. (1989). Data analysis: A model comparison approach. New York: Harcourt Brace Jovanovich.

Kiesler, D. J. (1983). The 1982 interpersonal circle: A taxonomy for complementarity in human transactions. Psychological Review, 90, 185-214.

Krueger, J. (2002). On the reduction of self-other asymmetries: Benefits, pitfalls and other correlates of social projection. Psychologica Belgica, 42, 23-41.

Krueger, J., \& Clement, R. W. (1994). The truly false consensus effect: An ineradicable and egocentric bias in social perception. Journal of Personality and Social Psychology, 67, 596-610.

Kunda, Z. (1990). The case for motivated reasoning. Psychological Bulletin, 108, 480-498.

LaPrelle, J., Hoyle, R. H., Insko, C. A., \& Bernthal, P. (1990). Interpersonal attraction and descriptions of the traits of others: Ideal similarity, self similarity, and liking. Journal of Research in Personality, 24, $216-240$

Leary, T. (1957). Interpersonal diagnosis of personality. New York: Ronald Press.

Leavitt, H. J. (2004). Top down: Why hierarchies are here to stay and how to manage them more effectively. Cambridge, MA: Harvard Business School Press.

Locke, K. D. (2003). Status and solidarity in social comparison: Agentic and communal values and vertical and horizontal directions. Journal of Personality and Social Psychology, 84, 619-631.

Locke, K. D., \& Sadler, P. (2007). Self-efficacy, values, and complementarity in dyadic interactions: Integrating interpersonal and social-cognitive theory. Personality and Social Psychology Bulletin, 33, 94-109.

Maner, J. K., Kenrick, D. T., Beckert, D. V., Robertson, T. E., Hofer, B., Neuberg, S. L., et al. (2005). Functional projection: How fundamental social motives can bias interpersonal perception. Journal of Personality and Social Psychology, 88, 63-78.

Markey, P. M., Funder, D. C., \& Ozer, D. J. (2003). Complementarity of interpersonal behavior in dyadic interactions. Personality and Social Psychology Bulletin, 29, 1082-1090.

Markus, H., \& Wurf, E. (1987). The dynamic self-concept: A social psychological perspective. Annual Review of Psychology, 38, 299-337.

Maslow, A. H. (1968). Toward a psychology of being. New York: Van Nostrand.

Miller, G., \& Marks, N. (1982). Target attractiveness as a mediator of assumed attitude similarity. Personality and Social Psychology Bulletin, $8,728-735$.

Mirels, J., \& Mills, J. (1964). Perception of the pleasantness and competence of a partner. Journal of Abnormal and Social Psychology, 68, $456-459$.

Moore, D. A., Kurtzberg, T. R., Thompson, L. L., \& Morris, M. W. (1999). Long and short routes to success in electronically mediated negotiations: Group affiliations and good vibrations. Organizational Behavior and Human Decision Processes, 77, 22-43.

Murray, S. L. (1999). The quest for conviction: Motivated cognition in romantic relationship. Psychological Inquiry, 10, 23-24.

Murray, S. L., \& Holmes, J. G. (1993). Seeing virtues in faults: Negativity and the transformation of interpersonal narratives in close relationships. Journal of Personality and Social Psychology, 65, 707-722.

Murray, S. L., \& Holmes, J. G. (1997). A leap of faith? Positive illusions in romantic relationships. Personality and Social Psychology Bulletin, $23,586-604$.

Murray, S. L., \& Holmes, J. G. (1999). The (mental) ties that bind:
Cognitive structures that predict relationship resilience. Journal of Personality and Social Psychology, 77, 1228-1244.

Murray, S. L., Holmes, J. G., \& Griffin, D. W. (1996). The benefits of positive illusions: Idealization and the construction of satisfaction in close relationships. Journal of Personality and Social Psychology, 70, 79-98.

Olson, J. M., Roese, N. J., \& Zanna, M. P. (1996). Expectancies. In E. T. Higgins \& A. W. Kruglanski (Eds.), Social psychology: Handbook of basic principles (pp. 211-238). New York: Guilford Press.

Robbins, J. M., \& Krueger, J. (2005). Social projection to ingroups and outgroups: A review of meta-analysis. Personality and Social Psychology Review, 9, 32-47.

Sadler, P., \& Woody, E. (2003). Is who you are who you're talking to? Interpersonal style and complementarily in mixed-sex interactions. Journal of Personality and Social Psychology, 84, 80-95.

Schwarz, N., Bless, H., Strack, F., Klumpp, G., Rittenauer-Schatka, H., \& Simons, A. (1991). Ease of retrieval as information: Another look at the availability heuristic. Journal of Personality and Social Psychology, 61, 195-202.

Sedikes, C. (1993). Assessment, enhancement, and verification determinants on the self-evaluation process. Journal of Personality and Social Psychology, 65, 317-338.

Stapel, D. A., \& Van der Zee, K. I. (2006). The self salience model of other-to-self effects: Integrating self-enhancement, complementarity, and imitation principles. Journal of Personality and Social Psychology, $90,258-271$.

Strong, S. R., Hills, H. I., Kilmartin, C. T., DeVries, H., Lanier, K., Nelson, B. N., et al. (1988). The dynamic relations among interpersonal behaviors: A test of complementarity and anticomplementarity. Journal of Personality and Social Psychology, 54, 798-810.

Taylor, S. E., \& Brown, J. D. (1988). Illusion and well-being: A social psychological perspective on mental health. Psychological Bulletin, 103, 193-210.

Thomas, G., Fletcher, G. J. O., \& Lange, C. (1997). On-line empathic accuracy in marital interactions. Journal of Personality and Social Psychology, 72, 839-850.

Tiedens, L. Z., Chow, R. M., \& Unzueta, M. M. (2007). Complementary contrast and assimilation: Interpersonal theory and the social functions of contrast and assimilation effects. In D. Stapel \& J. Suls (Eds.), Assimilation and contrast in social psychology. New York: Psychology Press.

Tiedens, L. Z., \& Fragale, A. R. (2003). Power moves: Complementarity in dominant and submissive nonverbal behavior. Journal of Personality and Social Psychology, 84, 558-568.

Tiedens, L. Z., \& Jimenez, M. C. (2003). Assimilation for affiliation and contrast for control: Complementary self-construals. Journal of Personality and Social Psychology, 85, 1049-1061.

Tracey, T. J. (1994). An examination of the complementarity of interpersonal behavior. Journal of Personality and Social Psychology, 67, 864-878.

Tyler, T. R., \& Sears, D. O. (1977). Coming to like obnoxious people when we must live with them. Journal of Personality and Social Psychology, $35,200-211$

Van Lange, P. A. M., Rusbult, C. E., Drigotas, S. M., Arriaga, X. B., Witcher, B. S., \& Cox, C. L. (1997). Willingness to sacrifice in close relationships. Journal of Personality and Social Psychology, 72, 1373-1395.

Weber, M. (1946). From Max Weber: Essays in sociology. New York: Oxford University Press.

Wiggins, J. S. (1979). A psychological taxonomy of trait-descriptive terms: The interpersonal domain. Journal of Personality and Social Psychology, 37, 395-412.

Wrzensniewski, A., \& Dutton, J. E. (2001). Crafting a job: Revisioning employees as active crafters of their work. Academy of Management Review, 25, 179-201.

Received August 30, 2004

Revision received January 22, 2007

Accepted February 2, 2007 